\title{
CORRECTION
}

\section{Correction: Maternal obesity and offspring cognition: the role of inflammation}

Carmen Monthé-Drèze ${ }^{1}$, Sheryl L. Rifas-Shiman ${ }^{2}$, Diane R. Gold ${ }^{3}$, Emily Oken ${ }^{2}$ and Sarbattama Sen ${ }^{1}$

Pediatric Research (2019) 85:904; https://doi.org/10.1038/s41390-019-0375-y

Correction to: Pediatric Research https://doi.org/10.1038/s41390018-0229-z, published online 12 November 2018
Following publication of this article, the authors noted that the name of the last author was incorrectly displayed as 'Sen Sarbattama'. This authors name has now been corrected to 'Sarbattama Sen'. This has been corrected in both the PDF and HTML versions of the article.

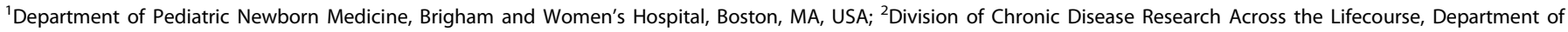

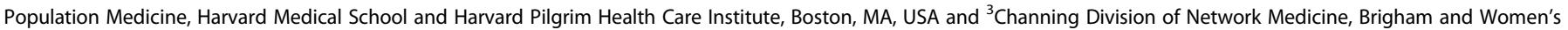
Hospital and Harvard Medical School, Boston, MA, USA

Correspondence: Carmen Monthé-Drèze (cmonthe-dreze@partners.org)

Published online: 22 March 2019 